\title{
ADSORPTION ISOTHERMS AND HYSTERESIS OF PROTON ADSORP- TION BY GOETHITE
}

\section{MADRID and P. DE ARAMBARRI}

Centro de Edafologia y Biologia Aplicada del Cuarto, Apartado 1052, Sevilla (Spain) (Received November 10, 1977; accepted June 22, 1978)

\section{ABSTRACT}

Madrid, L. and De Arambarri, P., 1978. Adsorption isotherms and hysteresis of proton adsorption by goethite. Geoderma, 21: 199-208.

The adsorption of $\mathrm{H}^{+}$ions by goethite is only partially reversible and the adsorption process is faster than desorption. The adsorption isotherm shows two inflexion points at $\mathrm{pH}$ values 7.5 and 9.5, which can be attributed to the existence of two or more types of $\mathrm{OH}$ groups on the surface with different basic strengths. The lack of reversibility is attributed to partial alterations of the surface by rearrangement of surface atoms although contributions of other phenomena to the overall process cannot be excluded.

\section{INTRODUCTION}

The adsorption of $\mathrm{H}^{+}$and $\mathrm{OH}^{-}$ions on oxide surfaces is a particularly important process because they are potential-determining ions on many mineral surfaces and because such adsorption has considerable influence on the adsorption and desorption of anions and cations and therefore on the dynamics of nutrients in soils.

Most papers devoted to this topic (Parks and De Bruyn, 1962; Parks, 1965; Atkinson et al., 1967) studied systems which were supposed to be at equilibrium. Exceptions are some papers by De Bruyn and colleagues (Onoda and De Bruyn, 1966; Bérubé et al., 1967; Bérubé and De Bruyn, $1968 \mathrm{a}, \mathrm{b})$, who studied the time-dependence of the adsorption of $\mathrm{H}^{+}$and $\mathrm{OH}^{-}$ions on oxide surfaces. The occurrence of hysteresis in the reaction is reported by Onoda and De Bruyn (1966). They observed a partial reversibility when hematite was successively titrated with base and acid or vice versa. It was attributed to diffusion of protons into or out of the solid.

Atkinson et al. (1967) developed an equation to explain the adsorption of potential-determining ions by goethite. They used electrochemical potentials of $\mathrm{H}^{+}$or $\mathrm{OH}^{-}$ions, respectively, at the acid or basic side of the zero point of charge (zpc), and those of the corresponding counter-ions, which in the present paper are $\mathrm{Cl}^{-}$and $\mathrm{Na}^{+}$ions. 
The equation for the acid side is:

$\Gamma_{\mathrm{H}}=k_{\mathrm{H}} V_{\mathrm{H}} \sqrt{\left(\mathrm{H}^{+}\right)(\mathrm{Cl})} \exp \left(-K_{1} \Gamma_{\mathrm{H}}\right)$

which can be rewritten in linear form: $\quad K_{1} \Gamma_{\mathrm{H}}$

$\log \Gamma_{\mathrm{H}}+1 / 2 \mathrm{pH}=\log \left(k_{\mathrm{H}} V_{\mathrm{H}}\right)+1 / 2 \log \left(\mathrm{Cl}^{-}\right)$

and for the basic side:

$\Gamma_{\mathrm{OH}}=k_{\mathrm{OH}} V_{\mathrm{OH}} \sqrt{\left(\mathrm{Na}^{+}\right)\left(\mathrm{OH}^{-}\right)} \exp \left(-K_{2} \Gamma_{\mathrm{OH}}\right)$

or:

$\log \Gamma_{\mathrm{OH}}-1 / 2 \mathrm{pH}=1 / 2 \log K_{\mathrm{W}}+\log \left(k_{\mathrm{OH}} V_{\mathrm{OH}}\right)+1 / 2 \log \left(\mathrm{Na}^{+}\right)-\frac{K_{2} \Gamma_{\mathrm{OH}}}{2.303}$

where $\Gamma_{\mathrm{H}}$ is the adsorbed amount of $\mathrm{H}^{+}, k_{\mathrm{H}}$ is a function of the change of standard chemical potential of $\mathrm{H}^{+}$ions during adsorption, $V_{\mathrm{H}}$ is the maximum amount of available sites at the surface for $\mathrm{H}^{+}$ions, $K_{1}$ is an interaction constant between surface and solution and $\Gamma_{\mathrm{OH}}, k_{\mathrm{OH}}, V_{\mathrm{OH}}$ and $K_{2}$ the corresponding magnitudes for $\mathrm{OH}^{-}$ions.

The model of Atkinson et al. (1967) requires certain assumptions, namely: the amount of counter-ions in the diffuse layer is negligible; $\Gamma_{H}$ is a linear function of the potential difference between the charged surface and the layer of counter-ions; the fraction of occupied sites is small and there are no differences in the reactivity or the energy of the $\mathrm{H}^{+}$adsorbing sites.

In the present paper some aspects of the adsorption of $\mathrm{H}^{+}$and $\mathrm{OH}^{-}$ions were studied, using goethite as an adsorbent, with special reference to the reversibility of the reaction. The suitability of the equations of Atkinson et al. (1967) is examined for the system studied here.

The reaction of $\mathrm{H}^{+}$or $\mathrm{OH}^{-}$ions on the surface of an iron oxide can be schematically described as:

$\underset{1}{\mathrm{Fe}}-\mathrm{OH} \underset{\mathrm{OH}^{-}}{\stackrel{\mathrm{H}^{+}}{\longrightarrow}} \mathrm{Fe}-\mathrm{OH}_{2}^{+}$

so that in the text below no distinction will be made between adsorption of $\mathrm{OH}^{-}$ions, desorption of $\mathrm{H}^{+}$ions, loss of positive charges and gain of negative charges.

\section{MATERIAL}

Goethite was prepared by the method reported by Atkinson et al. (1967). Pyrex glass vessels were used throughout and silicate concentration was always less than $10^{-5} \mathrm{M}$. The goethite precipitate was dialysed using deionized water until $\mathrm{NO}_{3}^{-}$could not be detected.

The goethite specific surface area was measured by $\mathrm{N}_{2}$ adsorption following the method of Brunauer et al. (1938) and was found to be $70.5 \mathrm{~m}^{2}$ 
$\mathrm{g}^{-1}$, and the zpc, as measured by the method given by Herrmann and Boehm (1969) was pH 8.71.

\section{METHODS}

\section{Adsorption isotherm}

The adsorption of $\mathrm{H}^{+}\left(\Gamma_{\mathrm{H}}\right)$ and $\mathrm{OH}^{-}\left(\Gamma_{\mathrm{OH}}\right)$ ions at each $\mathrm{pH}$ value were determined by the difference between the results of titrations of suspensions of $0.2 \mathrm{~g}$ of goethite in $50 \mathrm{ml}$ of $0.1 \mathrm{M} \mathrm{NaCl}$ with $0.1 M \mathrm{HCl}$ or $\mathrm{NaOH}$ and the results of blank titrations of $50 \mathrm{ml}$ of $\mathrm{NaCl} 0.1 \mathrm{M}$. Successive volumes of titrant added in a particular titration were regulated so that the maximum variation of $\mathrm{pH}$ was 0.2 to $0.3 \mathrm{pH}$ units per addition.

After every addition of titrant a fixed period of $10 \mathrm{~min}$ was allowed to elapse before the resulting $\mathrm{pH}$ value was read. Such $\mathrm{pH}$ values are not stabilized, even after some days, but the variations are much smaller after 10 min, which agrees with findings of Onoda and De Bruyn (1966). All experiments were performed under flushing wet $\mathrm{CO}_{2}$-free $\mathrm{N}_{2}$ gas, and the temperature was maintained at $20( \pm 1) \mathrm{C}$.

Adsorption densities $(\Gamma)$ at each $\mathrm{pH}$ were obtained by subtracting from $\Gamma_{\mathrm{H}}$ or $\Gamma_{\mathrm{OH}}$ its corresponding value at the zpc. The plot of the values of $\Gamma$ obtained in these experiments against $\mathrm{pH}$ gives a line which will be termed the "direct curve" (Figs. 1, 3 and 4).

\section{Reversibility}

The degree of reversibility of the adsorption of $\mathrm{H}^{+}$and $\mathrm{OH}^{-}$was observed by titrating suspensions of goethite in $0.1 \mathrm{M} \mathrm{NaCl}$ as above, to which given volumes of $0.1 \mathrm{M} \mathrm{NaOH}$ or $\mathrm{HCl}$ were added $10 \mathrm{~min}$ before starting the titration. Blank titrations were also carried out on $50 \mathrm{ml}$ of $0.1 \mathrm{M} \mathrm{NaCl}$ alone.

The calculation of the adsorption density at each $\mathrm{pH}$ value was made in the same manner as it was for the "direct curve". The plots of $\Gamma$ obtained in these experiments against pH will be termed "hysteresis curves".

\section{RESULTS AND DISCUSSION}

\section{Direct curve}

Fig. 1 shows the variation of the adsorption density, $\Gamma$ vs. $\mathrm{pH}$ (full line). This curve shows two inflexion points at $\mathrm{pH}$ values 7.5 and 9.5.

If the reaction of $\mathrm{H}^{+}$and $\mathrm{OH}^{-}$ions with the goethite surface followed eq. 1 and 2 , a straight line should be obtained by plotting $\left(\log \Gamma_{\mathrm{H}}+1 / 2 \mathrm{pH}\right.$ vs. $\left.\Gamma_{\mathrm{H}}\right)$ for the acid side of the zpc and $\left(\log \Gamma_{\mathrm{OH}^{-1 / 2}} \mathrm{pH}\right)$ vs. $\Gamma_{\mathrm{OH}}$ for the basic side. $\Gamma_{\mathrm{H}}$ and $\Gamma_{\mathrm{OH}}$ can be approximately obtained from $\Gamma$ data (At- 


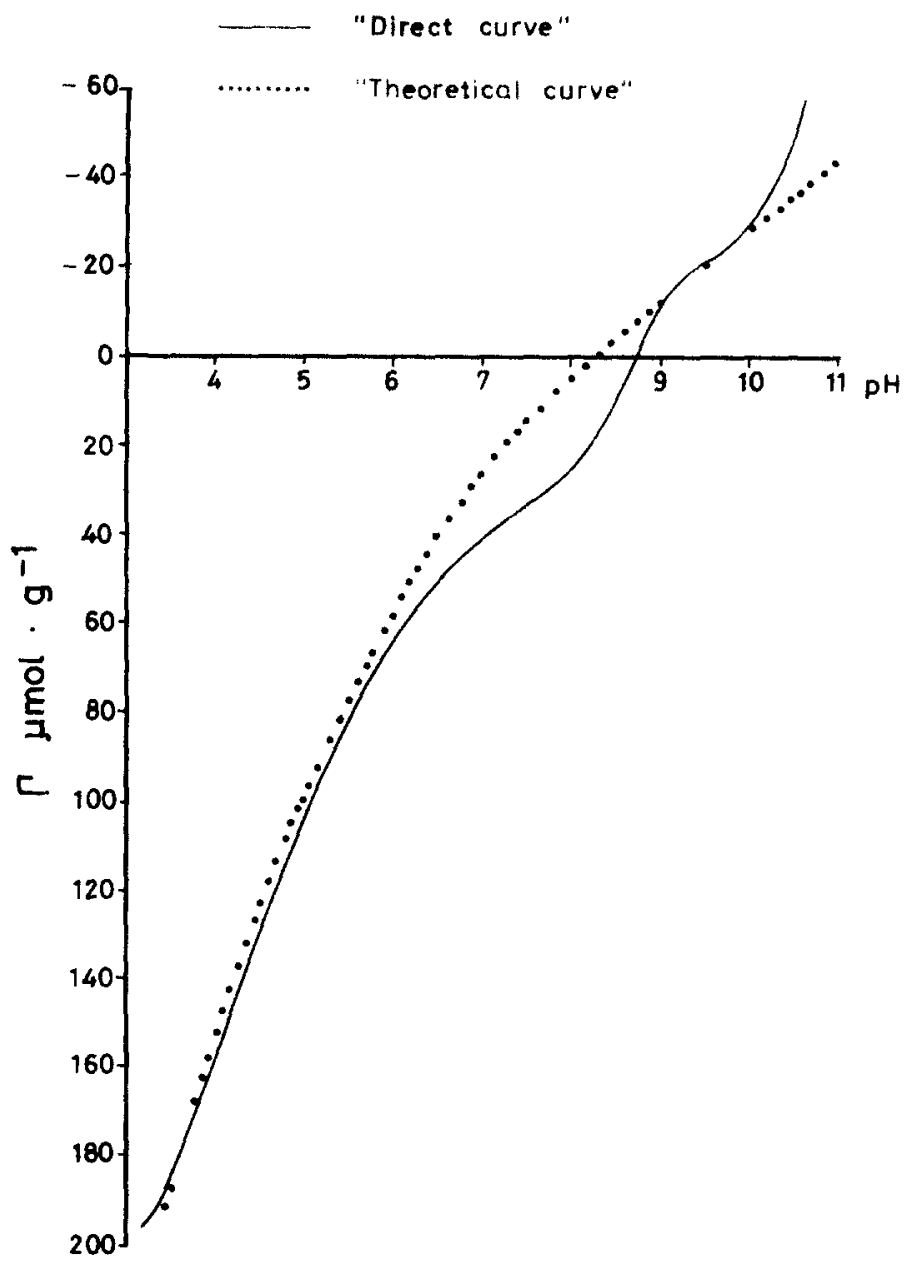

Fig. 1. Variation of adsorption densities $(\Gamma)$ with $\mathrm{pH},(-)$ experimental results, "direct curve"; (....) calculated from equation of Atkinson et al. (1967).

kinson et al., 1967). Results are shown in Fig. 2. Fig. 2A shows that the equation of Atkinson et al. (1967) fits the experimental data at the acid side well, but the equation is only followed within a narrow range of $\Gamma \mathrm{OH}$ values (from 40 to $60 \mu \mathrm{mol} \mathrm{g}^{-1}$ ) on the basic side (Fig. 2B).

The curves for $\Gamma_{\mathrm{H}}$ and $\Gamma_{\mathrm{OH}}$ against $\mathrm{pH}$ can be calculated from both straight lines and from those a "theoretical curve" for $\Gamma$ can be graphically obtained (Fig. 1, dotted line).

As can be seen in Fig. 1, the "theoretical curve" lies away from the "direct curve" in the neighbourhnod of the first inflexion point, $\mathrm{pH} \mathrm{7.5,}$ and both lines cross near the second inflexion point, $\mathrm{pH} 9.5$.

These two inflexion points can be due to two kinds of adsorption sites 


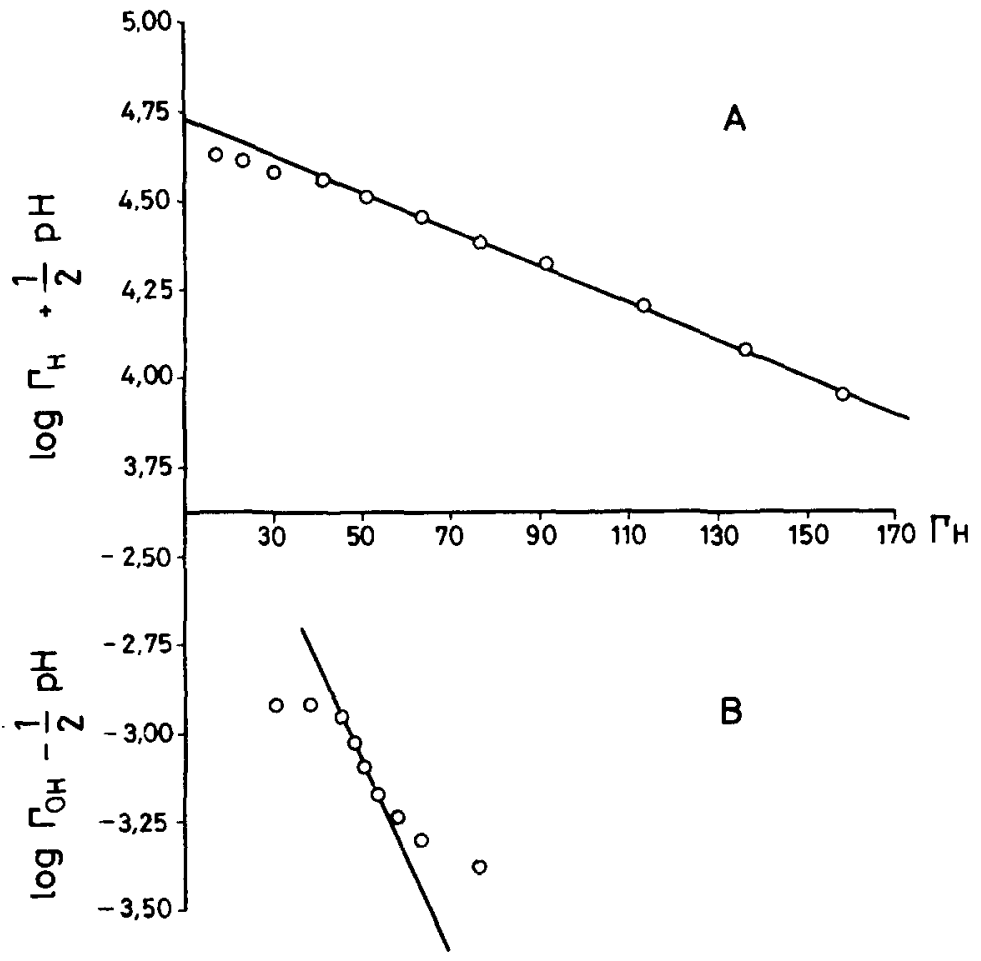

Fig. 2. Representation of experimental results according to: A. eq. 1, and B. eq. 2, from Atkinson et al. (1967).

with different proton affinities, that is to say, with different basic strengths. Russell et al. (1974) proposed a model for the goethite surface, according to which there exist three types of hydroxyl groups exposed on the (100) face, which predominates in the mineral. Such types of hydroxyl groups are named $\mathrm{A}, \mathrm{C}$ and $\mathrm{B}$ by the authors, and are respectively coordinated to one, two and three $\mathrm{Fe}^{3+}$ ions. This model has been confirmed by Parfitt et al. $(1975,1976)$. The different coordinations of the three types of hydroxyl groups should have different influences upon their acid-base behaviour, the higher positive charge near B- and C-groups diminishing the electronic density on the oxygen atoms. This implies that A-groups will be the most basic and B-groups the most acidic.

If it is presumed that the adsorption and desorption of protons take place predominantly on OH-groups of the (100) face, the behaviour of the direct curve suggests that only two out of the three types of OH-groups are neutralized. On the other hand, because the goethite mainly behaves as a proton acceptor, the inflexion points at $\mathrm{pH} 9.5$ can be adscribed to A-type $\mathrm{OH}$-groups and the one at $\mathrm{pH} 7.5$ to the C-type. The neutralization of $\mathrm{B}$ type hydroxyls should take place at lower $\mathrm{pH}$ values, those at which dissolution of the oxide would occur. 
Taking into account the surface area corresponding to an $\mathrm{OH}$-group of any type, $37 \mathrm{~A}^{2}$ according to Parfitt et al. (1976), and the specific surface area of the goethite that was studied, it can be calculated that $600 \mu \mathrm{mol}$ of $\mathrm{H}^{+}$ions should be consumed per gram of oxide if all A- and C-type $\mathrm{OH}$ groups react. Inasmuch as $\Gamma$ has a range of $260 \mu \mathrm{mol} \mathrm{g}^{-1}$ in these experiments, it can be postulated that only alternative positions of both $A$-and C-types react.

Therefore, it seems reasonable to affirm that the model of Atkinson et al. (1967) is not rigorously applicable to goethite, due to the existence of more than one type of hydroxyl group on its surface. Such different hydroxyl groups would cause $K_{1}$ and $K_{2}$ (eq. 1 and 2) to be a function of the proportion of occupied sites of each type, instead of being constants within the entire $\mathrm{pH}$ range as the authors suppose.

\section{Hysteresis curves}

Fig. 3 shows the results of titrations with $0.1 \mathrm{M} \mathrm{NaOH}$ after addition of two different volumes of $0.1 \mathrm{M} \mathrm{HCl}(0.1 \mathrm{ml}$ curve $1 b$ and $0.2 \mathrm{ml}$ curve $2 b)$. The full curve of Fig. 3 is the same direct curve as in Fig. 1.

The net positive charge of the surface as measured by the adsorption density $\Gamma$ is, at the initial $\mathrm{pH}$ value of both curves $1 b$ and $2 b$ of Fig. 3 , slightly lower than the expected value according to the direct curve. This fact implies that after the 10 min elapsed since initial addition of acid, the system has not yet reached the equilibrium given by the direct curve.

As soon as the titration with $0.1 \mathrm{M} \mathrm{NaOH}$ is started, both of curves $1 b$ and $2 b$ of Fig. 3 cross over the direct curve, and the positive charge becomes higher than that corresponding to the direct curve at any $\mathrm{pH}$ value. Above $\mathrm{pH} 9.5$ both hysteresis curves are indistinguishable and at this $\mathrm{pH}$ value there exists an inflexion point in each curve, but particularly noticeable for curve $1 b$.

The hysteresis observed here can be explained if it is supposed that the 10 min elapsed after each addition of $\mathrm{NaOH}$ are not enough to re-establish the equilibrium, so that part of the surface $\mathrm{OH}$-groups remain as $\mathrm{OH}_{2}$-groups and the surface is more positive (or less negative) than it should be according to the direct curve.

Fig. 4 shows the results of titrations with $0.1 \mathrm{M} \mathrm{HCl}$ after adding three different volumes of $0.1 \mathrm{M} \mathrm{NaOH}(0.1 \mathrm{ml}$, curve $1 a ; 0.15 \mathrm{ml}$, curve $1.5 a$ and $0.2 \mathrm{ml}$, curve $2 a$ ).

The net positive charge at the initial $\mathrm{pH}$ values of the three curves of Fig. 4 is clearly higher than the expected value according to the direct curve. This fact could be due to the slowness of the reaction of the surface $\mathrm{H}^{*}$ ions with the base added before titrating with $0.1 \mathrm{M} \mathrm{HCl}$, which agrees with the hysteresis observed in Fig. 3. This allows an excess of $\mathrm{OH}^{-}$to be present in solution.

The shape of curve $1 a$ of Fig. 4 suggests that the successive additions of 


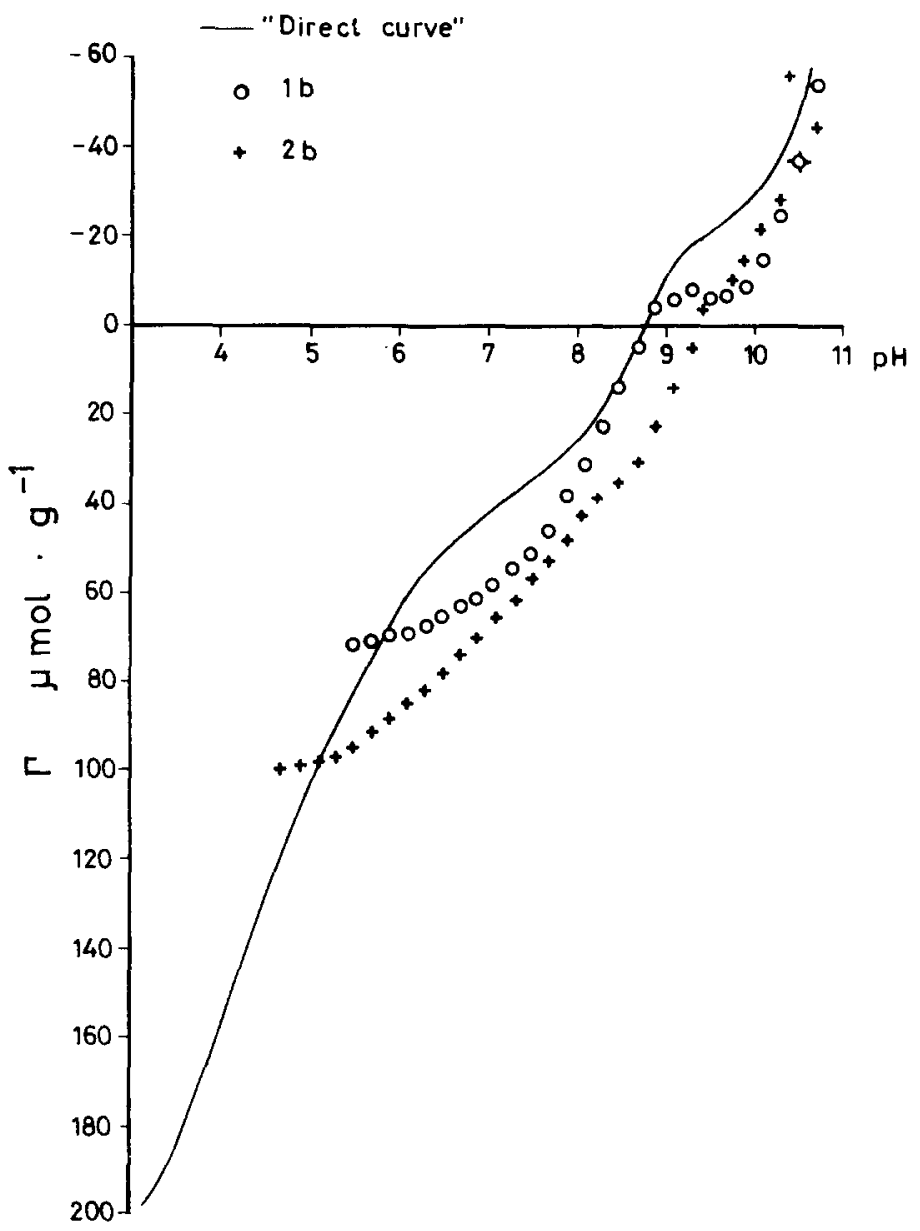

Fig. 3. Variation of adsorption densities $(\mathrm{r})$ with $\mathrm{pH}$ after acid addition: $(-)$ "direct curve"; $(0)$ "hysteresis curve" $1 b ;(+)$ "hysteresis curve $2 b$.

acid react with the $\mathrm{OH}^{-}$in solution in excess as much as with the surface $\mathrm{OH}^{-}$until the composition of the system comes close to the equilibrium given by the direct curve. Both curves are indistinguishable below $\mathrm{pH} 6$.

Instead, curve $2 a$ of Fig. 4 shows a marked hysteresis from the beginning of acid titration; the added acid seems to react only with the $\mathrm{OH}^{-}$ions in solution and the adsorption density stays nearly constant from $\mathrm{pH} 9.2$ to 6.9. Curve $2 a$ crosses over the direct curve, and the adsorption density maintains itself distinctly below the values expected from the direct curve. The gap between "hysteresis curve $2 a$ " and the "direct curve" is progressively narrower and the two are indistinguishable below pH 4.5. Curve $1.5 a$ of Fig. 4 is similar to curve $2 a$ but closer to the "direct curve" below pH 7.5.

All hysteresis curves in Fig. 4 show inflexion points at $\mathrm{pH} 7.5$. 


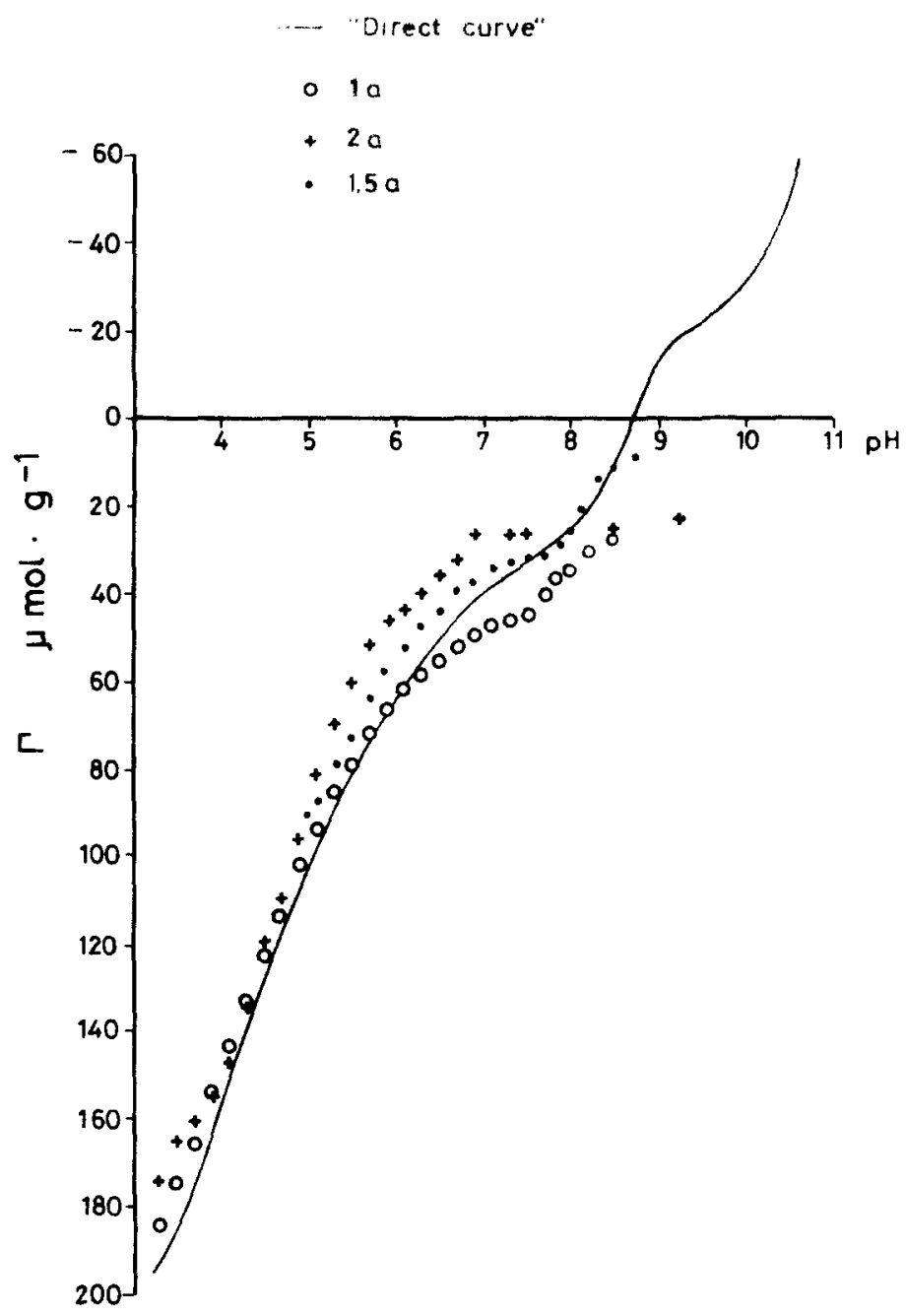

Fig. 4. Variation of adsorption densities $(\Gamma)$ with $\mathrm{pH}$ after base addition: $(-\rightarrow)$ "direct curve"; $(0)$ "hysteresis curve" $1 a ;(\bullet)$ "hysteresis curve" $1,5 a ;(+)$ "hysteresis curve" $2 a$.

The explanation put forward for the hysteresis represented by curves $1 b$ and $2 b$ of Fig. 3 is not in contradiction with the behaviour of curve $1 a$ of Fig. 4. Nevertheless, curves $1.5 a$ and $2 a$ of Fig. 4 show different characteristics which could be explained using the model of Russell et al. (1974).

As $0.15 \mathrm{ml}$ of $0.1 \mathrm{M} \mathrm{NaOH}$ are added to the goethite suspension, the oxide surface suddenly meets a high concentration of $\mathrm{OH}^{-}$ions. Under these conditions, despite the more acidic nature of C-type $\mathrm{OH}$-groups, some Atype groups are compelled to react, because these $\mathrm{OH}$-groups are the most 
accessible and their dissociation $\mathrm{pH}$ can be surpassed locally. As the acid titration is started the $\mathrm{pH}$ is progressively lowered, and the A-type $\mathrm{OH}$-groups take up $\mathrm{H}^{+}$ions from the C-type groups located in the neighbourhood (see Fig. 2 of Russell et al., 1974). The translocation of $\mathrm{H}^{+}$ions on the surface without consuming them from the solution would cause the solution to reach $\mathrm{pH}$ values more acidic than that corresponding to the positive charge of the surface. As soon as all A-type groups have been neutralized, reactions with $\mathrm{C}$-type $\mathrm{OH}^{-}$are resumed and the titration curve $1.5 a$ approaches and then joins the direct curve.

For a higher addition of base (curve $2 a$, Fig. 4) the process should be analogous but more noticeable. The amounts of A-type groups which lose $\mathrm{H}^{+}$in the first moment can be so high as to cause a screening effect that prevents the $\mathrm{C}$-type groups from reacting with added $\mathrm{OH}^{-}$ions. The long horizontal section in curve $2 a$ suggests that the rearrangement of $\mathrm{H}^{+}$ions on the surface occurs from the first addition of acid, probably due to such a screening effect.

The theory of Onoda and De Bruyn (1966) about the hysteresis of the adsorption and desorption of protons being due to diffusion processes into or out of the solid is not enough by itself to explain the different behaviour shown by the curves in Figs. 3 and 4 . The slowness of the desorption of $\mathrm{H}^{+}$ ions can be due to alterations of the surface at acidic $\mathrm{pH}$ values, which could promote rearrangements of surface $\mathrm{Fe}$ atoms and $\mathrm{OH}$ groups. This phenomenon would account for the masking of the inflexion point corresponding to the A-type groups at $\mathrm{pH} 9.5$ in curve $2 b$ of Fig. 3 inasmuch as these $\mathrm{OH}$ groups should be the most labile in such conditions.

On the other hand, the adsorption of $\mathrm{H}^{+}$ions after a considerable amount of base has been added seems to start on the A-type groups and afterwards a rearrangement of adsorbed protons can take place to slow down the uptake of new $\mathrm{H}^{+}$ions from solution.

\section{ACKNOWLEDGEMENTS}

Dr. J. Cornejo supplied data of zpc values of the goethite. We thank Dr. J. Cornejo, Dr. F. Cabrera and C.G. Toca for valuable advice.

\section{REFERENCES}

Atkinson, R.J., Posner, A.M. and Quirk, J.P., 1967. Adsorption of potential-determining ions at the ferric oxide-aqueous electrolyte interface. J. Phys. Chem., 71: 550-558.

Bérubé, Y.G. and De Bruyn, P.L., 1968a. Adsorption at the rutile-solution interface, I. Thermodynamics and experimental study. J. Coll. Interf. Sci., 27: 305-318.

Bérubé, Y.G. and De Bruyn, P.L., 1968b. Adsorption at the rutile-solution interface, II. Model of the electrochemical double layer. J. Coll. Interf. Sci., 28: 92-105.

Bérubé, Y.G., Onoda, G.Y. and De Bruyn, P.L., 1967. Proton adsorption at the ferric oxide-aqueous solution interface, II. Analysis of kinetic data. Surface Sci., 8: 448-461.

Brunauer, S., Emmett, P.H. and Teller, E., 1938. Adsorption of gases in multimolecular layers. J. Am. Chem. Soc., 60: 309-319. 
Herrmann, M. and Boehm, M.P., 1969. Über die Chemie der Oberfläche des Titandioxids, II. Saure Hydroxylgruppen auf der Oberfläche. Z. Anorg. Allgem. Chem., 336: 7386.

Onoda, G.Y. and De Bruyn, P.L., 1966. Proton adsorption at the ferric oxide-aqueous solution interface, I.A kinetic study of adsorption. Surface Sci., 4: 48-63.

Parfitt, R.L., Atkinson, R.J. and Smart, R.S.C., 1975. The mechanisms of phosphate fixation by iron oxides. Soil Sci. Soc. Am. Proc., 39: 837-841.

Parfitt, R.L., Russell, J.D. and Farmer, V.C., 1976. Confirmation of the surface structures of goethite $(\alpha-\mathrm{FeOOH})$ and phosphated goethite by infrared spectroscopy. J.C.S. Faraday I, 72: 1082-1087.

Parks, G.A., 1965. The isoelectric points of solid oxides, solid hydroxides and aqueous hydroxo complex systems. Chem. Rev., 65: 177-198.

Parks, G.A. and De Bruyn, P.L., 1962. The zero point of charge of oxides. J. Phys. Chem., 66: 967-973.

Russell, J.D., Parfitt, R.L., Fraser, A.R. and Farmer, V.C., 1974. Surface structure of gibbsite, goethite and phosphated goethite. Nature, 248: 220-221. 